\title{
Huganbuzure Granule Attenuates Concanavalin-A-Induced Immune Liver Injury in Mice via Regulating the Balance of Th1/ Th2/Th17/Treg Cells and Inhibiting Apoptosis
}

\author{
Mengheng Wang $\mathbb{D}^{1},{ }^{1}$ Hailong Yin, ${ }^{1,2}$ Yu Xia, ${ }^{1}$ Yijun Tu, ${ }^{1}$ Xinshuang Zou, ${ }^{1}$ Wanci Song, \\ Laichun Luo, ${ }^{1}$ Hezhen Wu, ${ }^{1}$ Yanfang Yang, ${ }^{1}$ Junfeng Zan, ${ }^{1}$ Yanwen Liu, ${ }^{1}$ Hanxiong Dan, ${ }^{1}$ \\ Qiang Yin $\mathbb{D}^{1,2}$ and Pengtao You $\mathbb{D}^{1}$ \\ ${ }^{1}$ Hubei Key Laboratory of Resources and Chemistry of Chinese Medicine, Hubei University of Chinese Medicine, Wuhan 430065, \\ Hubei, China \\ ${ }^{2}$ Xinjiang Uygur Pharmaceutical Co., Ltd, Wulumuqi 830001, China
}

Correspondence should be addressed to Qiang Yin; yinqiang@renfu.com.cn and Pengtao You; tptyou@hbtcm.edu.cn

Received 24 February 2021; Revised 30 July 2021; Accepted 16 August 2021; Published 8 September 2021

Academic Editor: Qi-Rui Wang

Copyright (c) 2021 Mengheng Wang et al. This is an open access article distributed under the Creative Commons Attribution License, which permits unrestricted use, distribution, and reproduction in any medium, provided the original work is properly cited.

\begin{abstract}
In Uygur medicine, Huganbuzure granule $(\mathrm{HBG})$ is one of the classical prescriptions for liver protection. However, its role in immune liver injury remains unknown. This study evaluates the effect of HBG on concanavalin-A- (ConA-) induced immune liver injury and investigates its protective underlying mechanism. BALB/c mice were randomly divided into five groups $(n=24$ mice per group): control, ConA, $1.6 \mathrm{~g} / \mathrm{kg} \mathrm{HBG}+\mathrm{ConA}, 3.2 \mathrm{~g} / \mathrm{kg} \mathrm{HBG}+\mathrm{ConA}$, and $6 \mathrm{mg} / \mathrm{kg}$ prednisolone + ConA. HBG was intragastrically administrated once daily for ten consecutive days, prior to ConA (20 mg/kg) injection. The levels of alanine aminotransferase (ALT), aspartate aminotransferase (AST), total bilirubin (TBIL), superoxide dismutase (SOD), and malondialdehyde (MDA) in mouse serum were measured after ConA injection. Moreover, liver-related mRNA levels were evaluated by qPCR. The detection of liver-related proteins was assessed by immunohistochemistry and western blot analysis. Compared with the ConA group, HBG reduced the mRNA expression of IL-17A and IFN- $\gamma$ and the protein expression of T-bet and ROR- $\gamma$ t. In addition, HBG increased the mRNA expression of IL-4 and TGF- $\beta$ and protein expression of GATA3 and Foxp3, indicating that HBG regulated the balance of Th1/Th2 and Th17/Treg. Furthermore, HBG alleviated immune liver injury by reducing oxidative stress, inhibiting apoptosis, and decreasing the expression of p-JNK, p-ERK, p-p38, p-JAK1, p-STAT1, p-STAT3, and IRF1. Our data suggested that HBG attenuated ConA-induced immune liver injury by regulating the immune balance and inhibiting JAK1/STATs/IRF1 signaling, thereby reducing apoptosis induced by JNK activation. The findings indicate that HBG may be a promising drug for immune liver injury.
\end{abstract}

\section{Introduction}

Immune liver injury is a progressive inflammatory disorder that is closely related to abnormal immune stimulation of liver cells, which may start with acute hepatitis that can eventually result in liver cirrhosis, liver cancer, and even death [1-4]. Although the etiology of immunological hepatic injury is not fully understood, emerging evidence has indicated that, during viral or autoimmune hepatitis, misdirected or excessive immune stimulation may lead to liver injury [5]. $\mathrm{CD}^{+} \mathrm{T}$ cells were essential for mediating adaptive immunity in response to a variety of pathogens [6]. Intravenous application of concanavalin A (ConA) in mice resulted in the activation of immature $\mathrm{CD} 4^{+} \mathrm{T}$ cells that subsequently differentiated into $T$ helper cells including Th1, Th2, Th17, and regulatory T cells (Treg) [7, 8]. In previous studies, it has been reported that Th1 and Th2 cells play an important role in immunological hepatic 
injury [9]. Moreover, previous studies have shown that imbalanced Treg and proinflammatory Th17 responses are crucial for the progression of immunological hepatic injury $[10,11]$. Furthermore, T cell imbalance has been considered a major cause of immunological liver injury in mice [12].

Apoptosis, as a major constituent of programmed cell death, plays an important role in ConA-induced immune liver injury [13]. Disturbances in the apoptotic process may directly or indirectly be related to the manifestation of a variety of diseases, including tumors and autoimmune diseases. Many factors can induce apoptosis, including radiation and drugs [14]. Several signaling pathways have been associated with the potential mechanism of ConA-induced immune liver injury [15-17].

Uygur medicine, one of the important treatment modalities to prevent and cure diseases in China for thousands of years, plays an important role in ensuring national health and national reproduction. In Uygur medicine, HBG is one of the classical prescriptions for liver protection. It is mainly composed of Foeniculum vulgare Mill. (Umbelliferae), Semen et radix cortex of Cichorium intybus L. (Compositae), Cuscuta chinensis Lam. (Convolvulaceae), and Semen et radix cortex of Apium graveolens $\mathrm{L}$. (Umbelliferae). HBG is widely used in the treatment of chronic liver disease [18]; however, the specific underlying mechanisms of HBG in liver protection have yet to be elucidated. The purpose of this study was to establish an immune liver injury model in mice to investigate the underlying mechanism of $\mathrm{HBG}$ in maintaining the homeostasis of Th1/Th2 and Treg/Th17 in mice and evaluate the antiapoptosis effects.

\section{Materials and Methods}

2.1. Materials. HBG was purchased from Xinjiang Uygur Pharmaceutical Co. Ltd. (Xinjiang, China). Prednisolone was purchased from Shanghai Yuanye Bio-Technology Co., Ltd. (Shanghai, China). ConA was obtained from SigmaAldrich (MO, USA). Kits for ALT, AST, TBIL, MDA, and SOD were purchased from the Nanjing Jiancheng Bioengineering Institute (Nanjing, China).

2.2. Animal Models and Drug Treatment. A total of 180 male $\mathrm{BALB} / \mathrm{C}$ mice, six-to-eight weeks old, $20 \pm 2 \mathrm{~g}$, were purchased from the Hubei Provincial Center for Disease Control and Prevention (Hubei, China). Mice were housed in an SPF grade environment that was maintained at a temperature of $24 \pm 2^{\circ} \mathrm{C}$ and $55 \%$ humidity under a $12 \mathrm{~h}$ light/dark cycle with free access to a chow diet and water. All animal experiments were performed based on the National Institutes of Health Guidelines and approved by the Committee on the Ethics of Animal Experiments of the Hubei University of Chinese Medicine. In brief, 120 mice of the experimental group were randomly divided into five groups ( $n=24$ mice per group): control, ConA, $1.6 \mathrm{~g} / \mathrm{kg}$ $\mathrm{HBG}+\mathrm{ConA}, 3.2 \mathrm{~g} / \mathrm{kg} \mathrm{HBG}+\mathrm{ConA}$, and $6 \mathrm{mg} / \mathrm{kg}$ prednisolone (positive control) + ConA. In the $\mathrm{HBG}$ and prednisone group, HBG (1.6 or $3.2 \mathrm{~g} / \mathrm{kg}$ ) and prednisone were, respectively, orally administered once daily for 10 consecutive days. The control group and the ConA group received the same volume of normal saline, and the same treatment scheme was followed. The method of animal model construction is based on previously report [19]: on day 11, all mice, except for mice in the control group, were administered $20 \mathrm{mg} / \mathrm{kg}$ ConA by tail vein injection. Subsequently, at two, four, and six hours, eight mice from each group were randomly selected and euthanized, and the liver and blood were collected for pathological detection. The same drug treatment schedule was used to determine the survival rate. Survival of 60 mice was closely observed for $12 \mathrm{~h}$ after $30 \mathrm{mg} / \mathrm{kg}$ ConA injection.

2.3. RNA Isolation and Quantitative Real-Time PCR Analysis. Total RNA was extracted from frozen liver tissues using Trizol reagent (Thermo Fisher Scientific, USA), according to the manufacturer's guidelines. RNA was reverse-transcribed using HiScript ${ }^{\circledR}$ III RT SuperMix (Vazyme biotechnology, Nanjing, China). Primers for each gene were designed using Primer Premier 5.0 design software (Premier, Canada) and synthesized by Sangon Biotech (Shanghai, China). The mRNA expression levels of target genes were determined by qPCR using ChamQ Universal SYBR qPCR Master Mix (Vazyme) and the following thermocycler conditions: predegeneration at $95^{\circ} \mathrm{C}$ for $30 \mathrm{~s}, 40$ cycles of denaturation of $95^{\circ} \mathrm{C}$ for $10 \mathrm{~s}$, and $60^{\circ} \mathrm{C}$ for $30 \mathrm{~s}$. This was followed by a melting curve of $95^{\circ} \mathrm{C}$ for $15 \mathrm{~s}, 60^{\circ} \mathrm{C}$ for $60 \mathrm{~s}$, and $95^{\circ} \mathrm{C}$ for $15 \mathrm{~s}$. To normalize gene expression, GAPDH served as an internal control. The relative quantification was determined by the $2^{-\Delta \Delta C T}$ method. The primers used for qPCR are listed below (forward primer and reverse primer, respectively): IFN- $\gamma, 5^{\prime}$-CTCTTCCTCATGGCTGTTTCT- $3^{\prime}, 5^{\prime}$ TTCTTCCACATCTATGCCACTT-3'; TNF- $\alpha, 5^{\prime}$-GAGTAGACAAGGTACAACCC-3', 5' -ACCCTCACACTCAGATCATC-3'; IL-6, 5'-CATGTTCTCTGGGAAATCGTGG-3', $5^{\prime}$ GTACTCCAGGTAGCTATGGTAC-3'; IL-1 $\beta, 5^{\prime}$-CATCCAGCTTCAAATCTCGCAG-3', 5' -CACACACCAGCAGGTTATCATC-3'; $I L-4,5^{\prime}$-TCTCGAATGTACCAGGAGCCATA TC-3', 5' -AGCACCTTGGAAGCCCTACAGA-3'; IL-17A, 5' GAGCTTCATCTGTGTCTCTGAT- $3^{\prime}, 5^{\prime}$-GCCAAGGGAGT TAAAGACTTTG-3'; TGF- $\beta, 5^{\prime}$-TCTGCATTGCACTTATG CTGA-3', $5^{\prime}$-AAAGGGCGATCTAGTGATGGA-3'; IFN- $\beta$, $5^{\prime}$-CTGGGTGGAATGAGACTATTGT-3', $5^{\prime}$-AAGTTCCTGAAGATCTCTGCTC-3'; GAPDH, 5'-CATGGCCTTCCG TGTTCCTA-3', 5' -CCTGCTTCACCACCTTCTTGAT-3'.

\subsection{Hematoxylin-Eosin and Immunohistochemical Staining.} For staining purposes, mouse liver tissues were harvested and fixed in $4 \%$ paraformaldehyde for $24 \mathrm{~h}$. Subsequently, the tissue was embedded in paraffin, cut into $5 \mu \mathrm{m}$ sections, and stained with hematoxylin-eosin ( $\mathrm{H}$ and $\mathrm{E}$ ) (Servicebio, \#G1005). For immunohistochemical staining, sections were deparaffinized and rehydrated with phosphate-buffered saline (PBS), followed by antigen retrieval. The sections were incubated with peroxidase blocking reagent for $15 \mathrm{~min}$, followed by incubation with $5 \%$ BSA for $30 \mathrm{~min}$ at room temperature. Next, sections were incubated overnight at $4^{\circ} \mathrm{C}$ with primary antibodies directed to the following: p-STAT1(1 : 100 dilution, Cell Signaling Technology, \#8826), 
p-STAT3 (1:100 dilution, Cell Signaling Technology, \#9145), p-JNK (1 : 200 dilution, Cell Signaling Technology, \#4668), T-bet (1:100 dilution, Absin Bioscience Inc., \#abs137236), IRF1 (1:100 dilution, Proteintech Group, \#11335-1-AP), GATA3 (1 : 500 dilution, Proteintech Group, \#10417-1-AP), and Foxp3 (1:500 dilution, Proteintech Group, \#22228-1-AP). Subsequently, sections were incubated with a secondary horseradish peroxidase- (HRP-) conjugated anti-rabbit IgG antibody (1:200 dilution, Cell Signaling Technology, \#4412) for $60 \mathrm{~min}$, respectively, and developed using DAB (Servicebio, \#G1212) as chromogen. Staining was visualized and images were acquired using a light microscope (Olympus, Japan).

2.5. TUNEL Assay. Apoptosis of liver tissues was assessed using the TUNEL assay (Roche, \#11684817910). In brief, liver tissues were collected and fixed in $10 \%$ buffered neutral formalin at room temperature for at least $24 \mathrm{~h}$ and embedded in paraffin. The tissue was cut into $4 \mu \mathrm{m}$ sections, deparaffinized, and stained with the TUNEL kit. To counterstain, the DAB kit (Servicebio, \#G1212) and hematoxylin were used. Sections were observed under a microscope, and images were taken.

2.6. Measurement of Reactive Oxygen Species in Liver Cells. The level of reactive oxygen species (ROS) in liver cells was determined using 2,7-dichlorodihydro fluorescent diacetate (DCFH-DA, Beyotime, China), following the manufacturer's guidelines. Sections were observed under a fluorescence microscope (Nikon, Japan), and images were taken.

2.7. Western Blot Analysis. For Western blot analysis, liver tissues were collected and homogenized with RIPA lysis buffer, followed by centrifugation at $12,000 \mathrm{rpm}$ to clear the lysates. Next, the protein concentration in the lysates was measured by a bicinchoninic acid (BCA) protein assay. Equal amounts of protein $(100 \mu \mathrm{g})$ were loaded on an SDSPAGE gel, separated, and transferred onto nitrocellulose (NC) membranes (Millipore, Burlington, MA, USA). The membranes were blocked with $5 \%$ BSA for $2 \mathrm{~h}$ at room temperature and then incubated overnight at $4^{\circ} \mathrm{C}$ with primary antibodies, including ROR- $\gamma \mathrm{t}$ (1:1000 dilution, Proteintech Group, \#13205-1-AP), JAK1 (1 : 1000 dilution, Cell Signaling Technology, \#3344), p-JAK1 (1 : 1000 dilution, Cell Signaling Technology, \#74129), p-ERK (1:1000 dilution, Cell Signaling Technology, \#4695), p-p38 (1:1000 dilution, Cell Signaling Technology, \#9910), and cleaved caspase-3 (1 : 1000 dilution, Cell Signaling Technology, Danvers, \#9661). The membranes were washed and then incubated with secondary HRP-conjugated anti-rabbit IgG antibody (1:200 dilution, Cell Signaling Technology, \#4412) for $1 \mathrm{~h}$ at room temperature. The membranes were washed three times with Tris-buffered saline + Tween (TBST) for $10 \mathrm{~min}$. Proteins were visualized by the addition of ECL (Thermo), and membranes were scanned and imaged by the FluorChem FC3 system (ProteinSimple, USA).
2.8. Statistical Analysis. Statistical significance was assessed using the Student's $t$-test and one-way ANOVA. The type of $t$-test is two-tailed, equal variance independent-samples $t$ test. All statistical analyses were performed using SPSS 22.0 software (IBM, USA). Data were expressed as the mean \pm SD. All experiments were repeated in triplicate, and $p<0.05$ was considered significant.

\section{Results}

3.1. HBG Attenuates ConA-Induced Immunological Liver Injury in Mice. After the injection of ConA, the survival rate of mice in each group was observed for $12 \mathrm{~h}$. As shown in Figure 1(a), the survival rate of mice in the ConA group was significantly lower compared with that of mice in the control group $(p<0.01)$, indicating that HBG effectively improved the survival rate of mice compared with mice in the ConA group $(p<0.05$ or $p<0.01)$. Moreover, our data showed that serum levels of ALT, AST, and TBIL significantly increased in the ConA group at all time points and reached a peak at $4 \mathrm{~h}(p<0.01)$ (Figures $1(\mathrm{~b})-1(\mathrm{~d}))$. However, the increase in ALT, AST, and TBIL expression was reversed by treatment with HBG. Compared with mice in the ConA group, serum levels of ALT, AST, and TBIL of mice that were pretreated with $\mathrm{HBG}$ significantly decreased $(p<0.01)$. To further determine the protective effect of $\mathrm{HBG}$ on liver injury, $\mathrm{H}$ and E staining of liver tissues was performed. Our data demonstrated that in ConA-treated mice, the liver showed massive signs of hepatocyte death, inflammatory cell infiltration, and structural liver damage (Figure 1(e)). However, in the treatment group, only minor slight liver injury was observed. Treatment with HBG, especially, significantly reduced liver necrosis. Taken together, these results showed that HBG effectively reduced ConA-induced immune liver injury in mice.

3.2. HBG Inhibits the Production of Inflammatory Cytokines and Regulates Immune Cell Disorder. In general, ConA-induced liver injury is related to the release of inflammatory cytokines [20]. Therefore, qPCR was used to determine the expression of inflammatory factors in mouse liver. As shown in Figure 2, a significant increase in hepatic IL- $1 \beta$, TNF- $\alpha$, IFN- $\gamma$, and IL-17A was observed at all time points in mice in the ConA group compared with mice in the control group and reached a peak at $4 \mathrm{~h}$ after ConA injection $(p<0.01)$. Moreover, the expression of IL- 4 and TGF- $\beta$ decreased significantly at all time points and reached the lowest value at $4 \mathrm{~h}$ after ConA injection $(p<0.01)$. Treatment with HBG significantly decreased mouse hepatic levels of IL- $1 \beta$, TNF$\alpha$, IFN- $\gamma$, and IL-17A mRNA compared with mice in the ConA group $(p<0.01)$ (Figures $2(\mathrm{a})-2(\mathrm{c})$ and $2(\mathrm{e}))$ and increased hepatic levels of IL- 4 and TGF- $\beta(p<0.05$ or $p<0.01$ ) (Figures 2(d) and 2(f)). Thus, these findings suggested that the hepatoprotective effect of HBG on ConAinduced liver injury in mice may in part be due to the inhibition of inflammatory factors and regulation of immunerelated cytokines. Figures $2(\mathrm{~g})$ and $2(\mathrm{j})$ show that, compared with mice in the control group, the positive expression of 

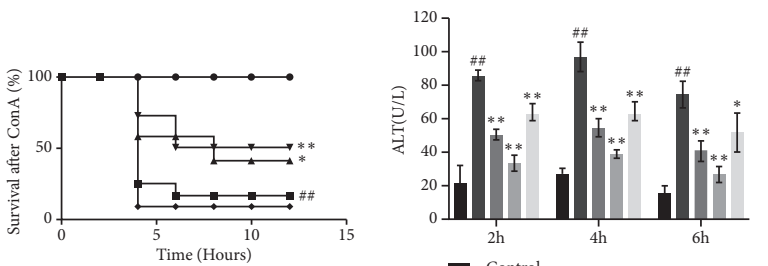

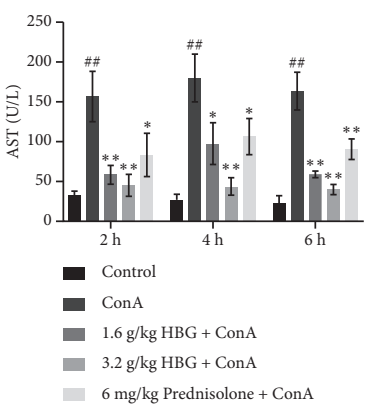

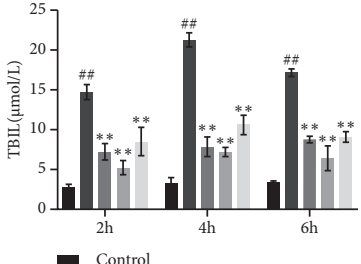

- Control

- $\operatorname{Con} A$

$1.6 \mathrm{~g} / \mathrm{kg} \mathrm{HBG}+$ ConA

- $3.2 \mathrm{~g} / \mathrm{kg} \mathrm{HBG}+\mathrm{ConA}$

- $6 \mathrm{mg} / \mathrm{kg}$ Prednisolone + ConA (a)

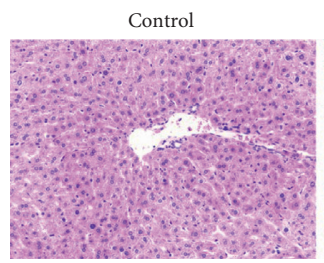

(b) (c)

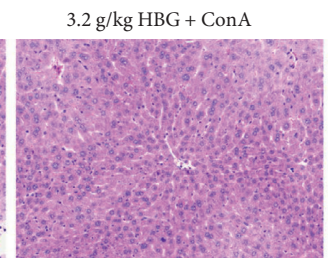

(d)

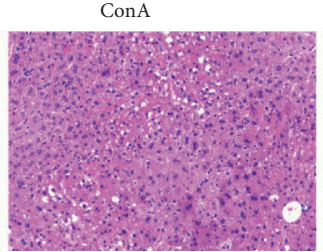

$1.6 \mathrm{~g} / \mathrm{kg} \mathrm{HBG}+\mathrm{Con} A$

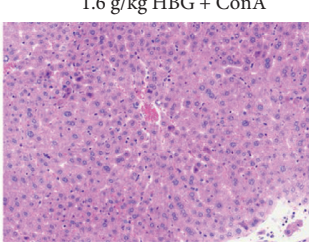

$6 \mathrm{mg} / \mathrm{kg}$ Prednisolone + ConA

(e)

Figure 1: HBG attenuates ConA-induced immunological liver injury in mice. (a) Twelve-hour survival of mice after injection with $30 \mathrm{mg} / \mathrm{kg}$ of ConA. (b-d) Serum levels of ALT, AST, and TBIL in serum of mice. (e) H\&E staining of mouse liver tissue $(\times 200)$. Data were expressed as the mean \pm SD. ${ }^{\# \#} p<0.01$ vs. the control group. ${ }^{*} p<0.05$ and ${ }^{* *} p<0.01$ vs. the ConA group.

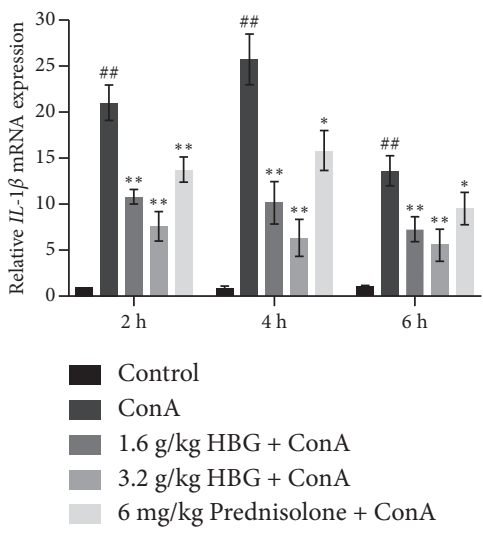

(a)

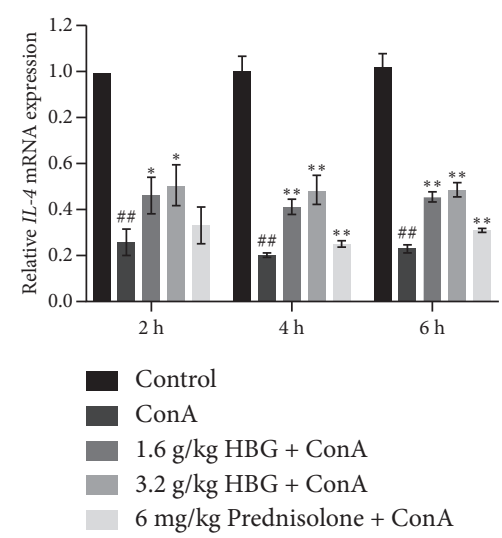

(d)

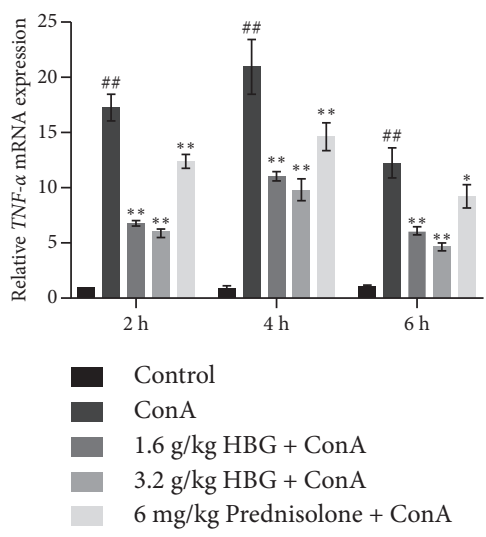

(b)

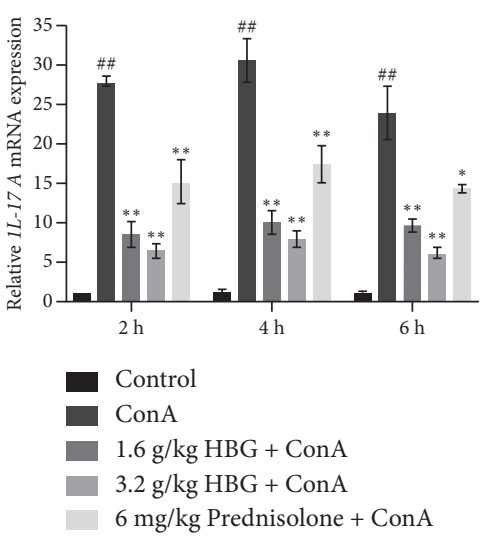

(e)

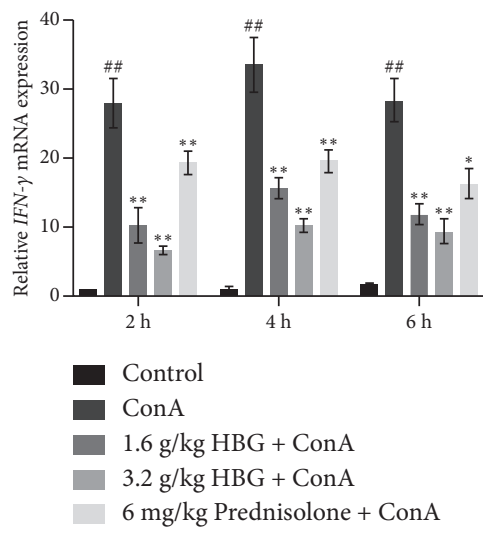

(c)

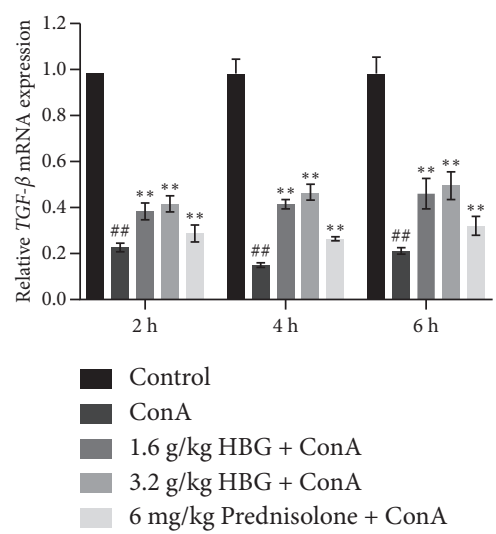

(f)

FIgURE 2: Continued. 

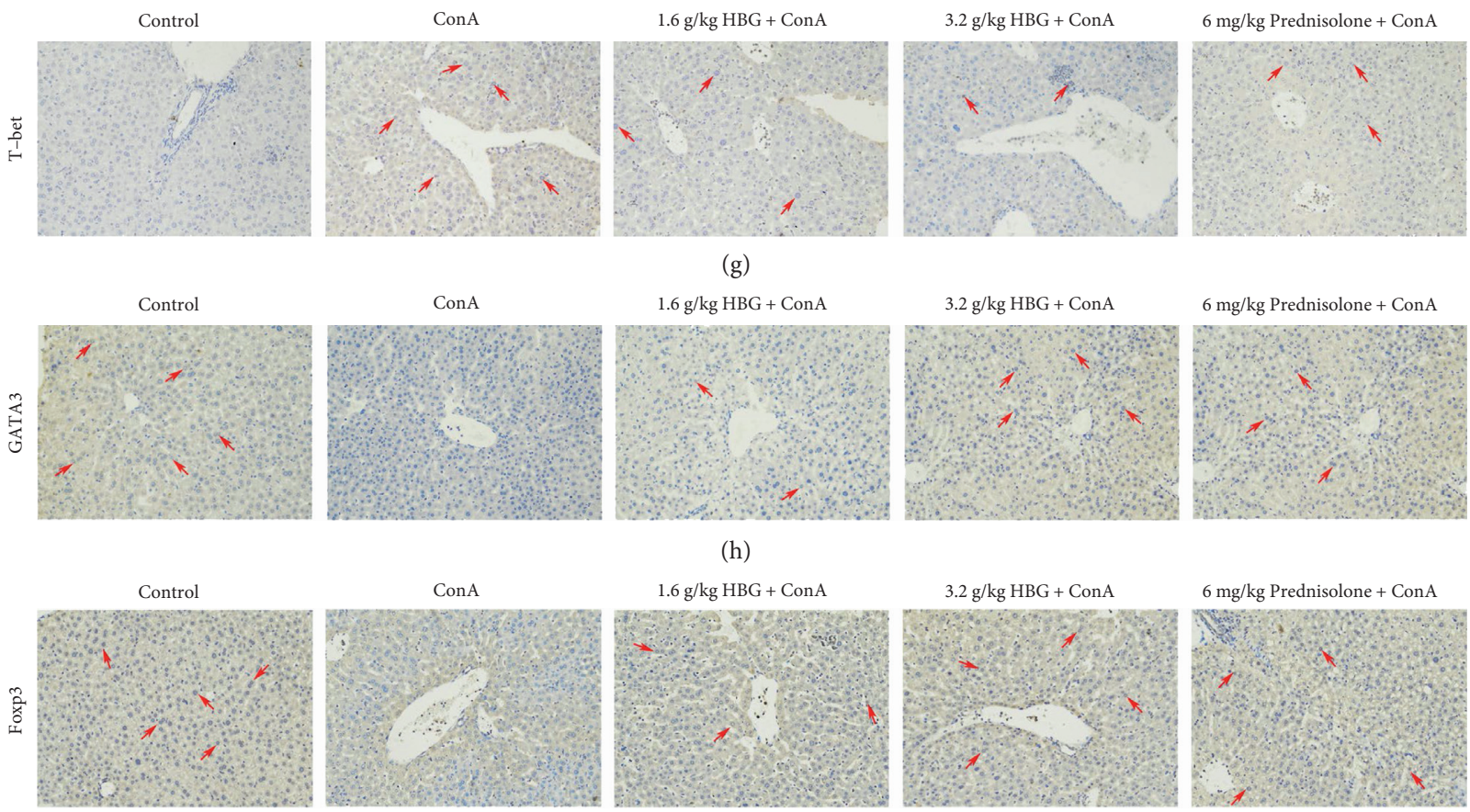

(h)
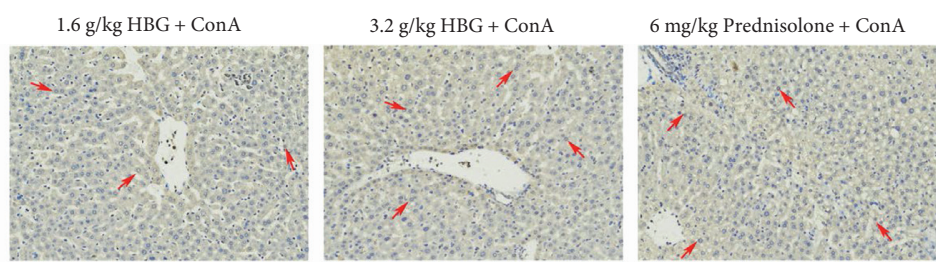

(i)

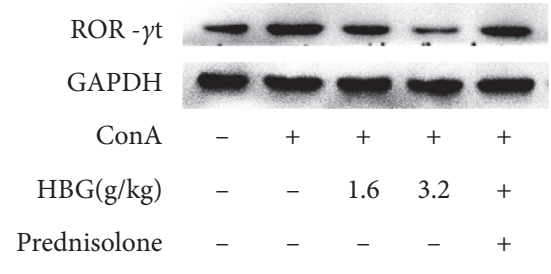

(j)

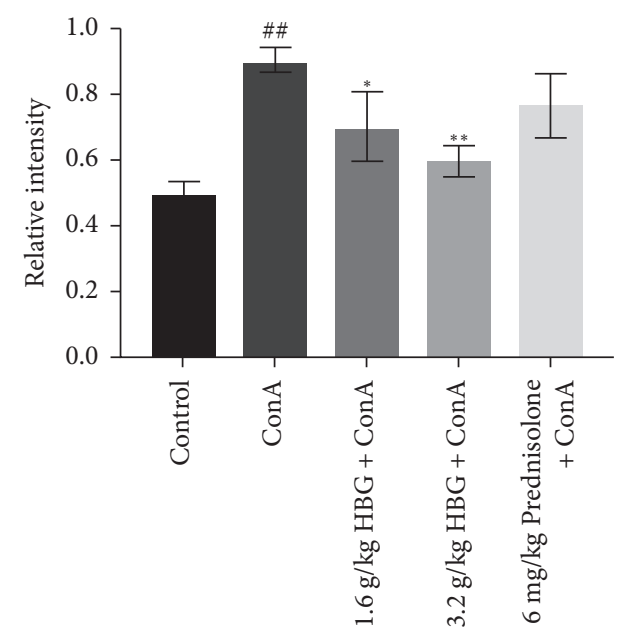

(k)

FIgURE 2: HBG inhibits the production of inflammatory cytokines and regulates the immune cell disorder. (a,b) The mRNA expression levels of IL- $1 \beta$ and TNF- $\alpha$ were detected by qPCR, normalized to control $(2 \mathrm{~h})$ values. (c-f) The mRNA expression levels of IFN- $\gamma$, IL-4, IL$17 \mathrm{~A}$, and TGF- $\beta$ were detected by qPCR, normalized to control $(2 \mathrm{~h})$ values. $(\mathrm{g}-\mathrm{i})$ Immunohistochemical staining $(\times 200)$ showing the expression of T-bet, GATA3, and Foxp3 in liver tissue at $4 \mathrm{~h}$ after ConA injection. (j, k) The expression of ROR- $\gamma$ t proteins was determined by western blot analysis, and gray values were calculated. ${ }^{\# \#} p<0.01$ vs. the control group. ${ }^{*} p<0.05$ and ${ }^{* *} p<0.01$ vs. the ConA group.

T-bet and ROR- $\gamma \mathrm{t}$ in mice in the ConA group was significantly increased. Furthermore, expression levels of T-bet and ROR- $\gamma$ t in T cells was reduced in mice in the HBG groups compared with mice in the ConA group. Figures 2(h) and 2(i) show that the positive expression of GATA3 and Foxp3 was significantly reduced after ConA injection. However, treatment with HBG significantly increased the positive expression of GATA3 and Foxp3 compared with 
that of mice in the ConA group. Taken together, these results suggested that HBG protected against liver injury by inhibiting the production of inflammatory factors and regulating the balance of immune cells.

\subsection{HBG Suppresses the JAK1/STATs/IRF1 Signaling} Pathway. IL-6 can regulate immune responses, acute phase responses, and hematopoietic function and plays an important role in the body's anti-infective immune response [21]. Figures 3(a) and 3(b) show that, at all time points, a significant increase in hepatic IL- 6 and IFN- $\beta$ was observed in the ConA group compared with that of mice in the control group and reached a peak at $4 \mathrm{~h}$ after ConA injection $(p<0.01)$. HBG significantly decreased hepatic levels of IL-6 and IFN- $\beta$ mRNA compared with that of mice in the ConA group $(p<0.01)$. As shown in Figures 3(c) and 3(d), HBG reduced the $\mathrm{p}$-JAK1 expression in mice with liver injury; however, no significant differences were observed in the expression of total JAK1 between groups. Next, we evaluated the phosphorylation of STAT1 and STAT3 in mouse liver tissues. The data showed that positive expression of p-STAT1 and p-STAT3 was increased in mice in the ConA group compared with mice in the control group. However, HBG effectively downregulated the positive expression of p-STAT1 and p-STAT3, relative to mice in the ConA group (Figures 3(e) and 3(f)). The immunohistochemical data indicated that IRF1 was highly expressed in mice in the ConA group; however, HBG treatment decreased the positive expression of IRF1 to different degrees (Figure 3(g)).

3.4. HBG Inhibits Hepatocyte Apoptosis Induced by JNK Activation. Previous studies have shown that oxidative stress can induce apoptosis [22]. In our study, significant oxidative stress of hepatocytes was observed in mice with liver injury. In brief, we first measured levels of SOD and MDA in mouse liver tissue. The results showed that the MDA content in mice in the ConA group increased at all time points and reached a peak at $4 \mathrm{~h}$ after ConA administration $(p<0.01)$. However, administration of 1.6 and $3.2 \mathrm{~g} / \mathrm{kg}$ HBG effectively inhibited the MDA content at all time points $(p<0.05$ or $p<0.01)$ (Figure $4(a))$. The SOD activity was significantly decreased at all time points in the Con $\mathrm{A}$ group and reached the lowest value at $4 \mathrm{~h}$ after ConA administration $(p<0.01)$ (Figure $4(\mathrm{~b}))$. Interestingly, the SOD activity was markedly increased by treatment with HBG at all time points $(p<0.01)$. Subsequently, ROS levels in the liver were examined with DCFH-DA staining using frozen liver sections. Figure 4(c) shows ROS levels at three time points. Compared with the control group, mice in the ConA group showed a significantly higher level of ROS, which reached a peak at $4 \mathrm{~h}$ after ConA administration. However, HBG treatment markedly decreased the elevated ConA-induced ROS levels at all time points.

To determine whether $\mathrm{p}$-JNK was involved in ConAinduced liver injury, p-JNK expression was evaluated by immunohistochemical staining. Figure 4(d) shows that, compared with the control group, significantly increased expression of $\mathrm{p}-\mathrm{JNK}$ was observed in mice in the ConA group. However, HBG treatment effectively decreased the increased expression of p-JNK. As shown in Figures 4(e) and 4(f), the protein expression of p-ERK and p-p38 in mice in the ConA group was higher compared with that in the control group $(p<0.01)$. HBG significantly downregulated the increase of $\mathrm{p}$-ERK and $\mathrm{p}$-p38 protein expression $(p<0.05$ or $p<0.01)$.

Simultaneously, we studied the effect of HBG on the apoptosis of mouse liver induced by ConA. TUNEL assay was performed to determine the apoptosis of mouse liver cells. Figure 4(g) shows a high number of TUNEL-positive hepatocytes existing in mice in the ConA group compared with mice in the control group. Interestingly, TUNEL staining also showed clear improvement of apoptosis in HBG-treated mice. To further explore the effect of HBG on ConA-induced apoptosis of liver cells, we investigated cleaved caspase- 3 protein in mouse liver. Our data showed that, compared with mice in the control group, the protein expression of cleaved caspase- 3 in mice in the ConA group was significantly increased $(p<0.01$ ) (Figures $4(\mathrm{~h})$ and $4(\mathrm{i})$ ). Thus, HBG markedly downregulated the protein expression of cleaved caspase-3.

\section{Discussion}

Immune liver injury is a type of inflammatory disease [20]. The incidence is increasing, and immune liver injury has become an important burden in the world that possesses a serious threat to human life. Our findings demonstrated that HBG effectively protected liver function, regulated immune balance, and inhibited apoptosis caused by oxidative stress, thereby alleviating ConA-induced immune liver injury in mice.

The increase in ALT and AST serum levels caused by hepatocyte division is a sign of pathological damage [23]. HBG significantly decreased ALT and AST levels, as well as causing liver necrosis in mice with liver injury. In the process of immune liver injury, the activation of inflammatory cells starts, which is characterized by direct cytotoxicity or the release of proinflammatory cytokines, thereby inducing liver injury $[24,25]$. The protective role of $\mathrm{HBG}$ in ConA-induced liver injury has also been related to its strong anti-inflammatory effect.

$\mathrm{T}$ lymphocytes play a significant role in immune liver injury and can differentiate into Th1, Th2, Th17, and Treg cells [26]. Intrahepatic tolerogenic immune responses regulate pro- and anti-inflammatory immune balance and maintain intrahepatic balance [27]. However, when this balance is disrupted, excessive immune activation can lead to acute liver failure [5]. Intrahepatic IFN- $\gamma$ is an important cytokine that can induce T-cell-dependent liver injury, is secreted by Th1 cells, and has been reported as a key mediator in the pathogenesis of ConA-induced liver injury $[28,29]$. IL-4 is an important cytokine secreted by Th2, and the imbalance of Th1/Th2 has become an important factor in immune liver injury [30]. An imbalance in Treg and Th17 is also a key factor in the development of immune liver injury $[31,32]$. Th17 has been recognized as a proinflammatory cell, and IL-17A was secreted by Th17. Our study showed 


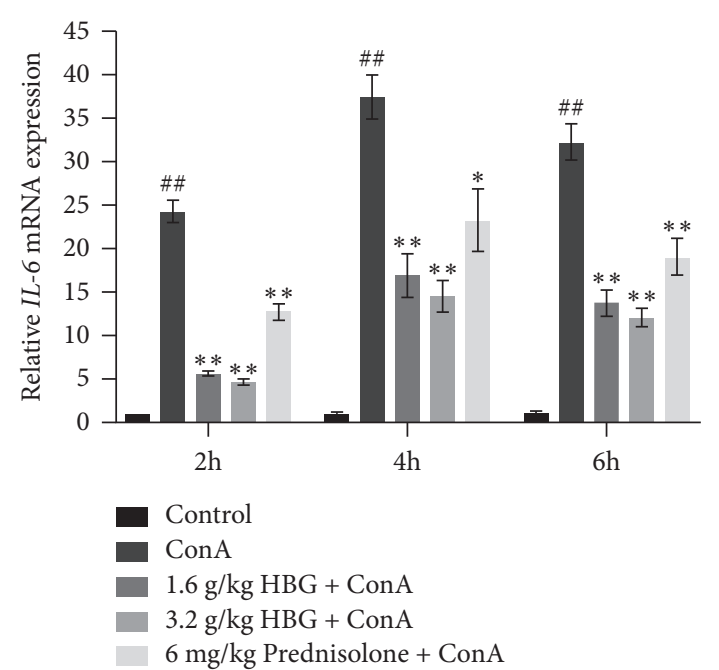

(a)

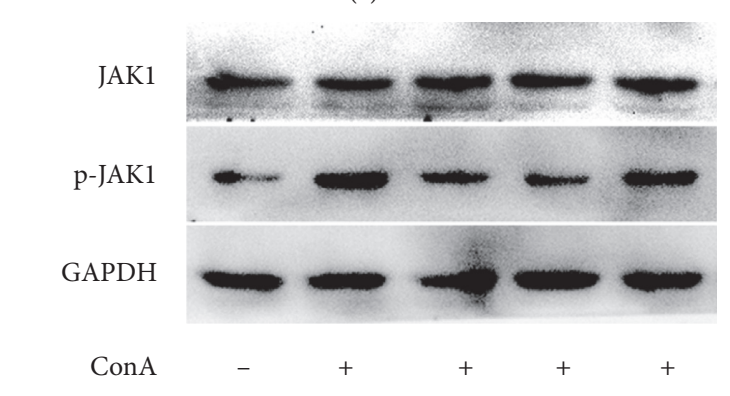

$\mathrm{HBG}(\mathrm{g} / \mathrm{kg}) \quad-\quad \quad-\quad \begin{array}{llll}- & 1.6 & 3.2 & -\end{array}$

Prednisolone

(c)
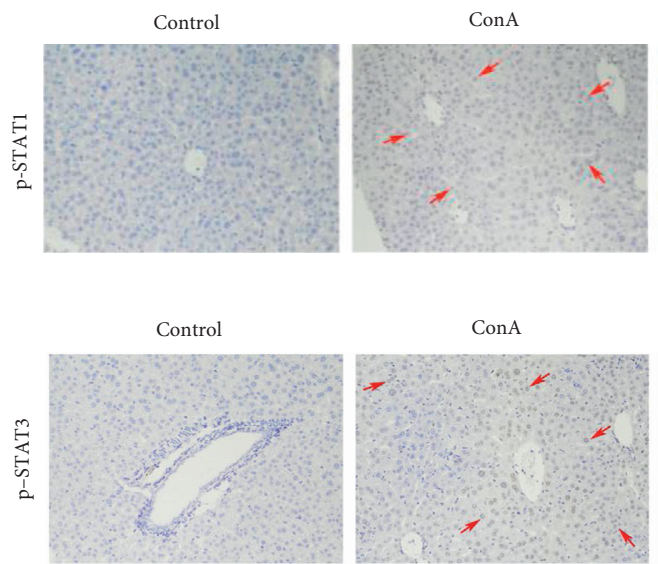

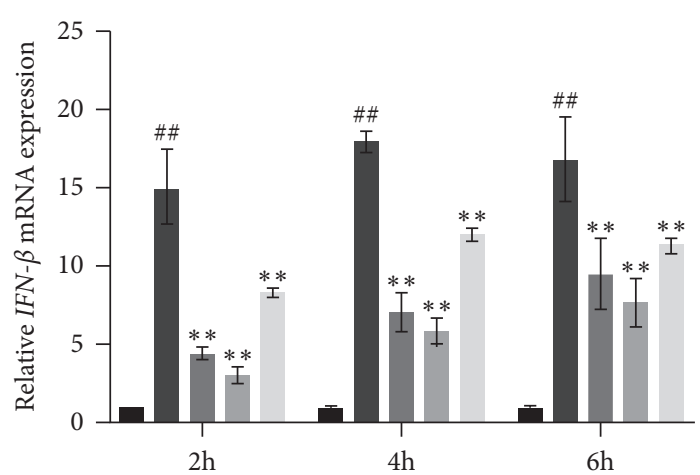

$$
\begin{aligned}
& \text { Control } \\
& \text { ConA } \\
& 1.6 \mathrm{~g} / \mathrm{kg} \mathrm{HBG}+\text { Con } \mathrm{A} \\
& 3.2 \mathrm{~g} / \mathrm{kg} \mathrm{HBG}+\text { Con } \mathrm{A} \\
& 6 \mathrm{mg} / \mathrm{kg} \text { Prednisolone + ConA }
\end{aligned}
$$

(b)

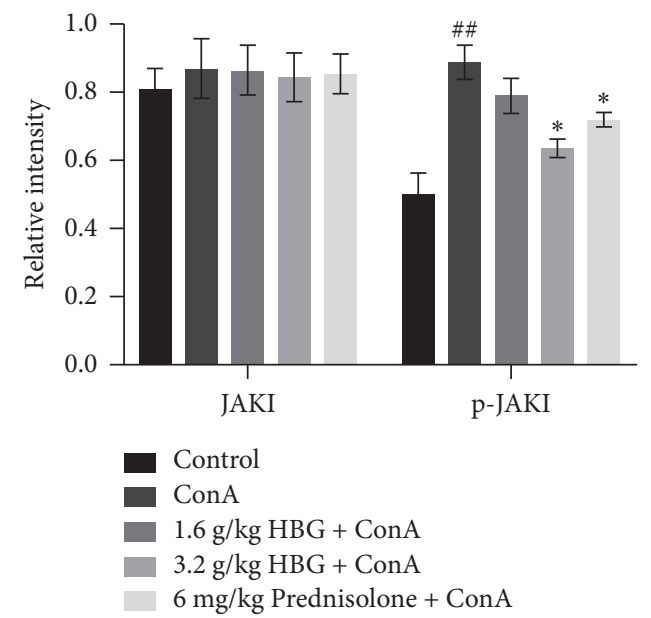

(d)

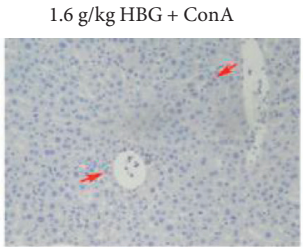

$3.2 \mathrm{~g} / \mathrm{kg} \mathrm{HBG}+\mathrm{ConA}$

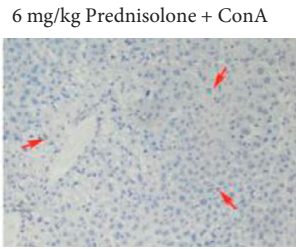

(e)

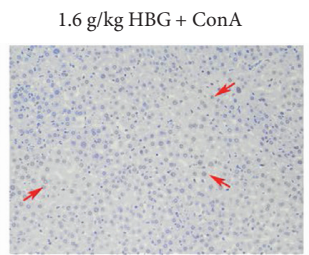

$3.2 \mathrm{~g} / \mathrm{kg} \mathrm{HBG}+\mathrm{ConA}$

$6 \mathrm{mg} / \mathrm{kg}$ Prednisolone + ConA

(f)

FIgURE 3: Continued. 

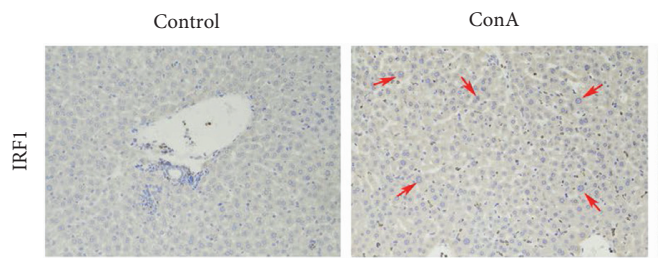

$1.6 \mathrm{~g} / \mathrm{kg} \mathrm{HBG}+$ ConA

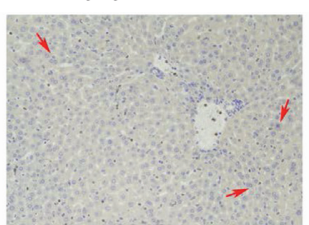

(g)
$3.2 \mathrm{~g} / \mathrm{kg} \mathrm{HBG}+\mathrm{ConA}$

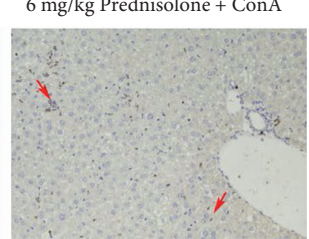

FIGURE 3: HBG suppresses the JAK1/STATs signaling pathway. (a, b) In each group, mRNA expression levels of IL-6 and IFN- $\beta$ were detected by qPCR, normalized to control $(2 \mathrm{~h}$ ) values. (c, d) The expression of JAK1 and p-JAK1 was determined by western blot analysis, and gray values were calculated. (e-g) Immunohistochemical staining $(\times 200)$ showing the expression of p-STAT1, p-STAT3, and IRF in liver tissue at $4 \mathrm{~h}$ after ConA injection. ${ }^{\# \#} p<0.01$ vs. the control group. ${ }^{*} p<0.05$ and ${ }^{* *} p<0.01$ vs. the ConA group.

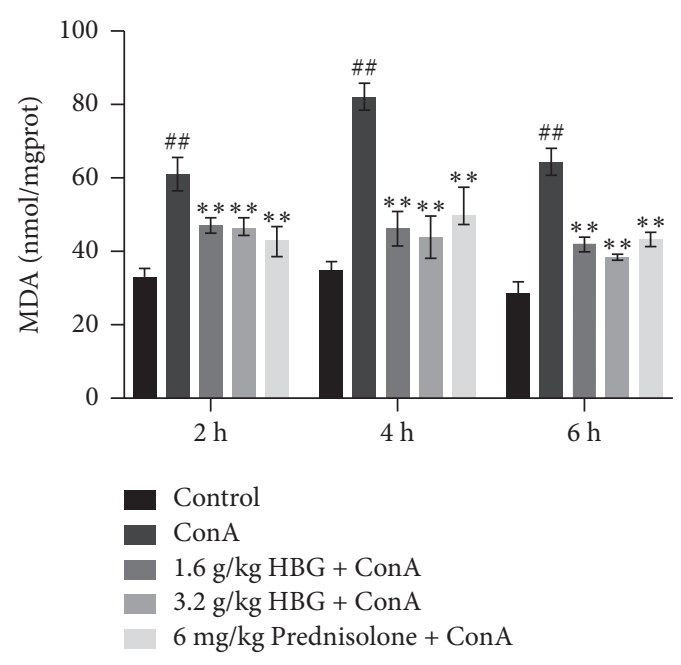

(a)

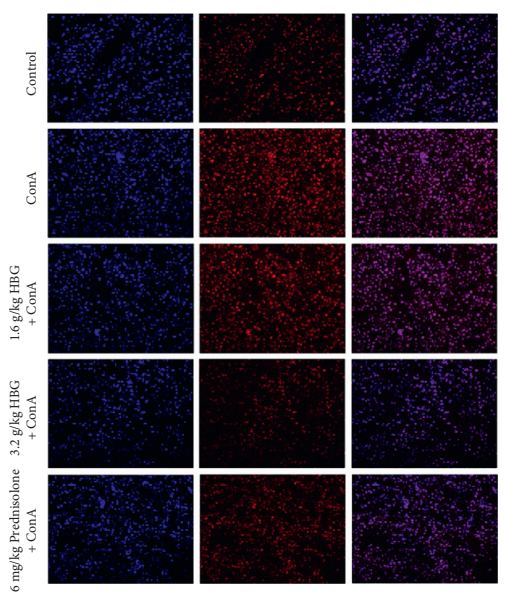

Control

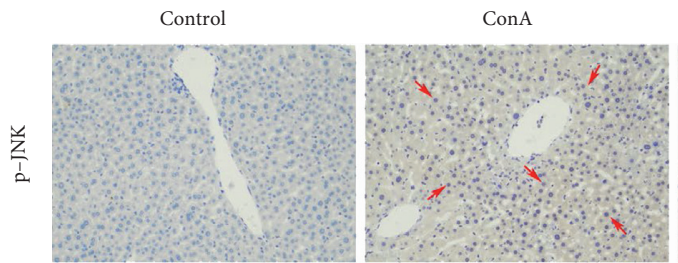

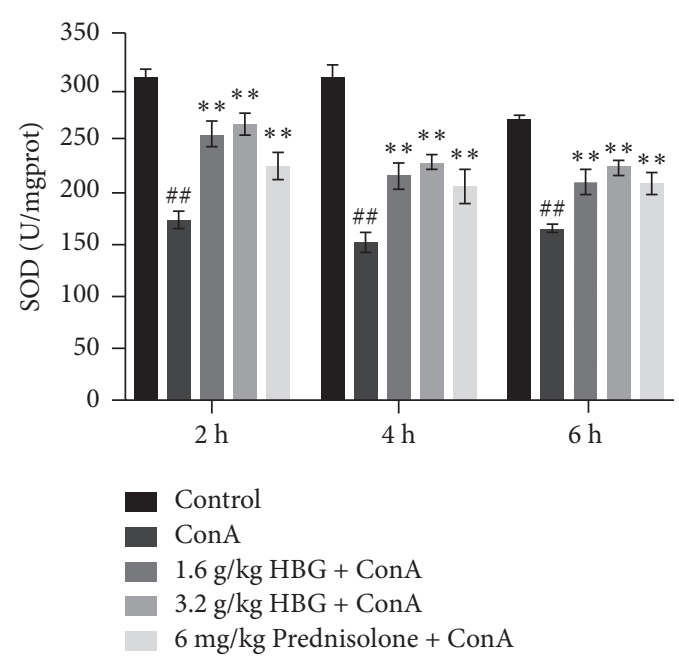

(b)
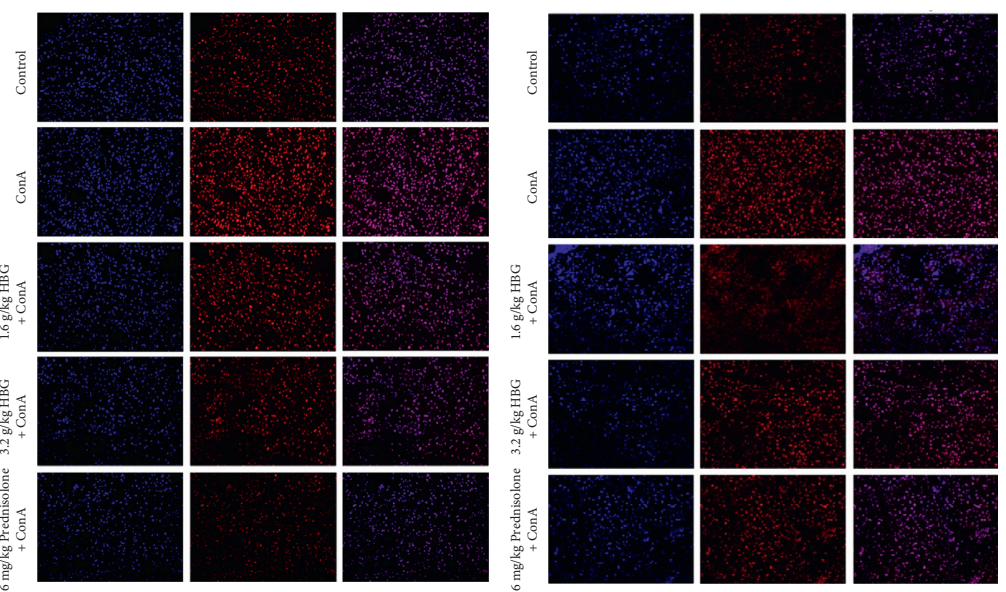

(c)

$1.6 \mathrm{~g} / \mathrm{kg} \mathrm{HBG}+\mathrm{ConA}$

$3.2 \mathrm{~g} / \mathrm{kg} \mathrm{HBG}+\mathrm{ConA}$

$6 \mathrm{mg} / \mathrm{kg}$ Prednisolone + ConA
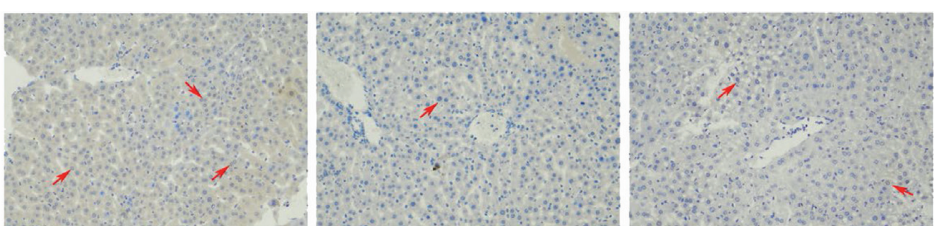

(d)

FIgURE 4: Continued. 


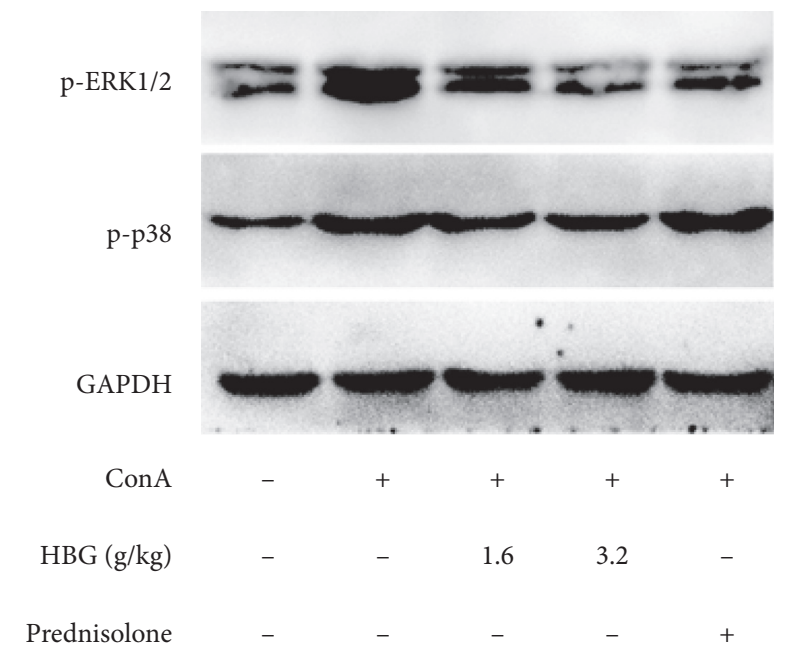

(e)
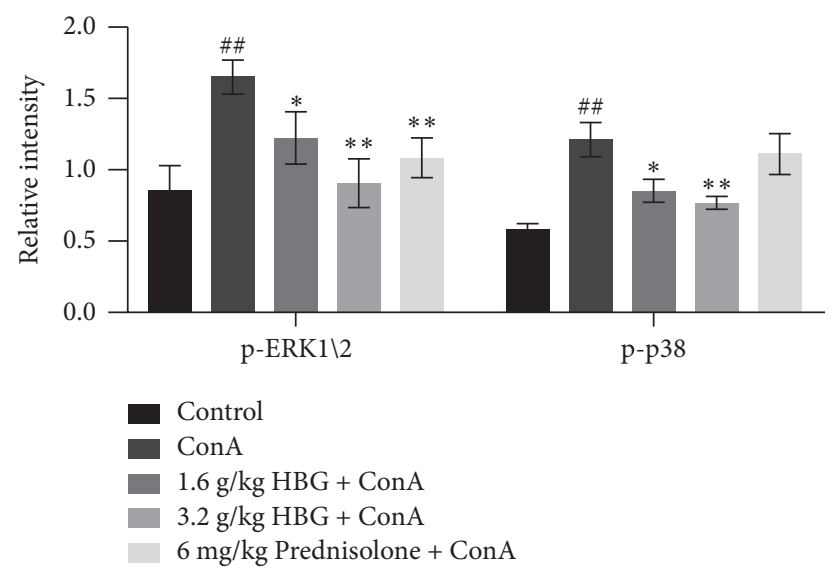

(f)

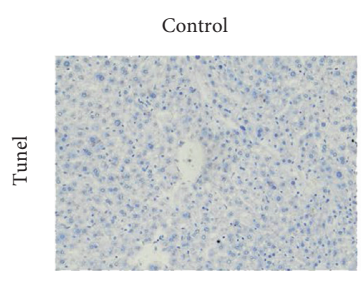
ConA $1.6 \mathrm{~g} / \mathrm{kg} \mathrm{HBG}+\mathrm{ConA}$
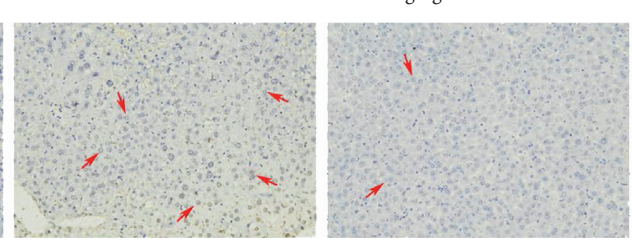
$3.2 \mathrm{~g} / \mathrm{kg} \mathrm{HBG}+\mathrm{ConA}$ $6 \mathrm{mg} / \mathrm{kg}$ Prednisolone + ConA

(g)

Cleaved-caspase3

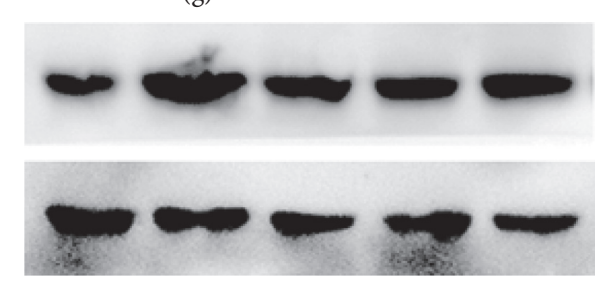

GAPDH
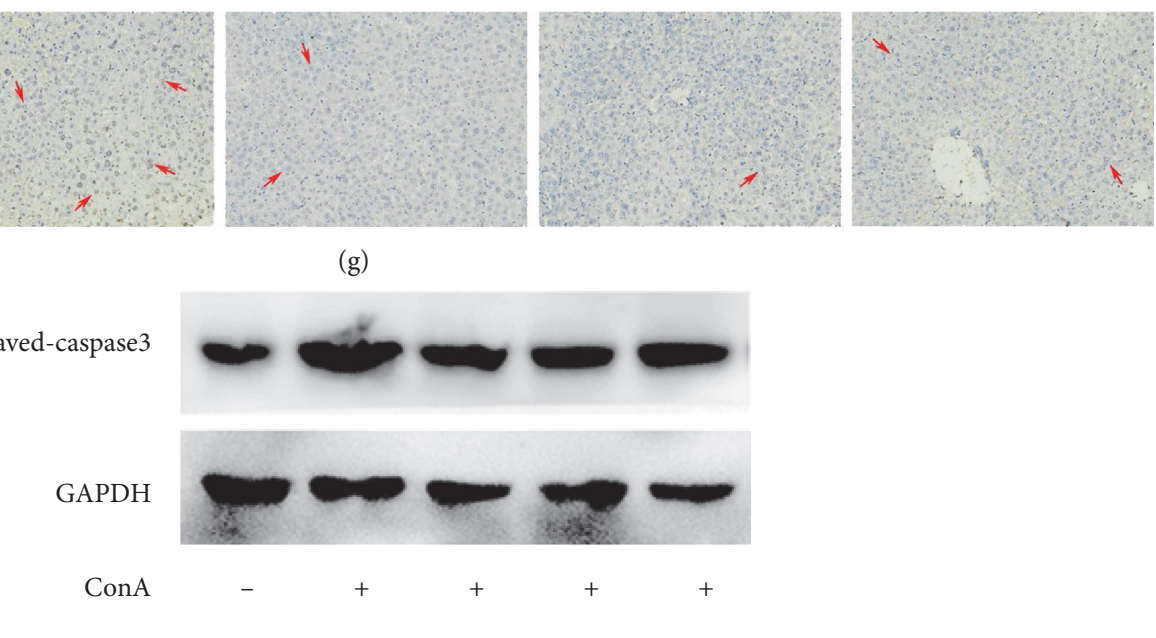

$\begin{array}{cccccc}\mathrm{HBG}(\mathrm{g} / \mathrm{kg}) & - & - & 1.6 & 3.2 & - \\ \text { Prednisolone } & - & - & - & - & +\end{array}$

(h)

FIgURE 4: Continued. 


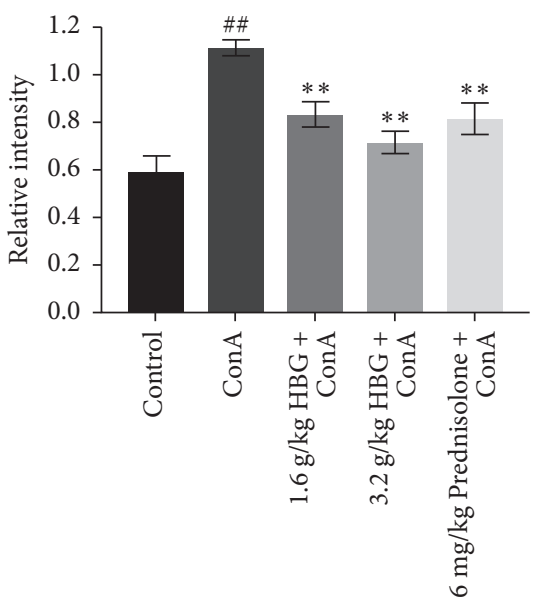

(i)

Figure 4: HBG inhibits hepatocyte apoptosis induced by JNK activation. (a, b) Serum levels of MDA and SOD. (c) Reactive oxygen species (ROS) fluorescence staining $(\times 200)$ showing ROS levels in the liver. (d) Immunohistochemical staining $(\times 200)$ showing the expression of pJNK in liver tissue at $4 \mathrm{~h}$ after ConA injection. (e, f) The expression of p-p38 and p-ERK1/2 proteins was determined using western blot analysis, and gray values were calculated. $(\mathrm{g})$ TUNEL staining $(\times 200)$ showing apoptotic cells in five groups at $4 \mathrm{~h}$ after ConA injection. (h, i) The expression of cleaved caspase- 3 protein was determined using western blot analysis, and gray values were calculated. ${ }^{\# \#} p<0.01$ vs. the control group. ${ }^{*} p<0.05$ and ${ }^{* *} p<0.01$ vs. the ConA group.

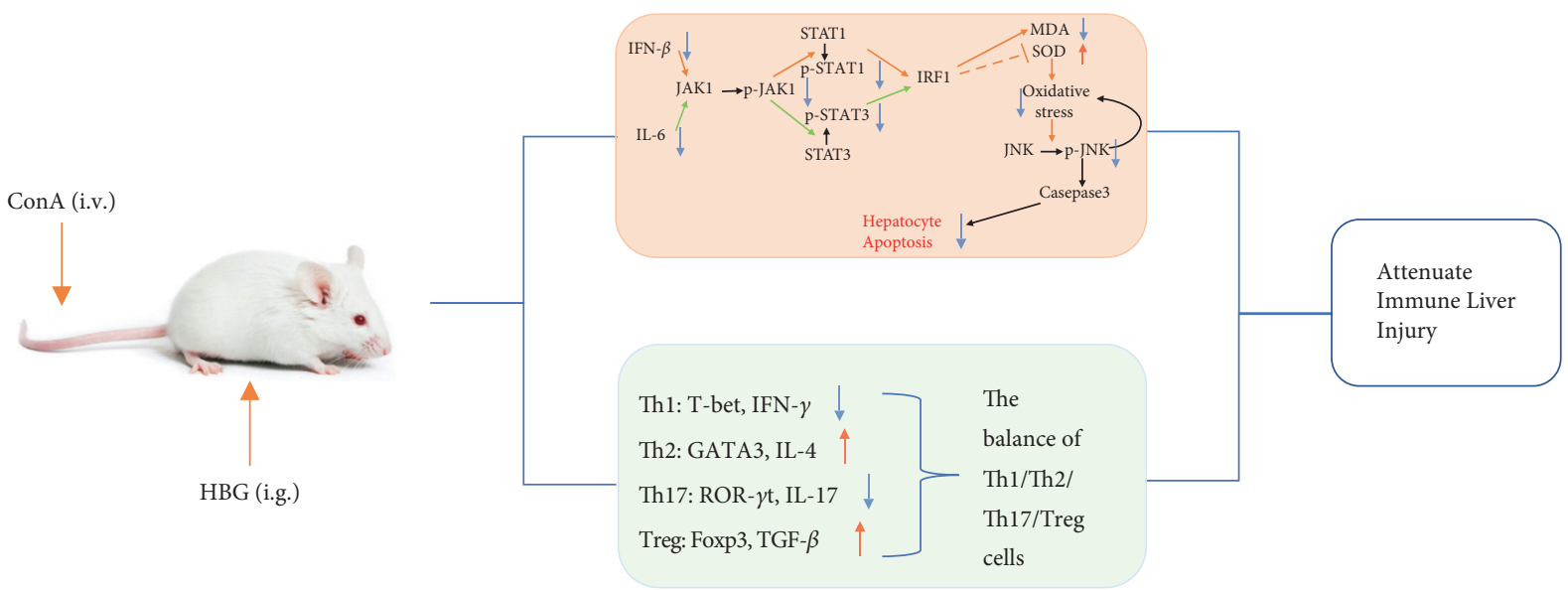

FIGURE 5: Schematic illustration of the protective mechanism of HBG on immune liver injury in mice.

that HBG significantly reduced the expression of IFN- $\gamma$ and T-bet in the liver of ConA-injected mice and, simultaneously, upregulated the expression of IL-4 and GATA3 in the liver. However, HBG significantly reduced the expression of IL-17A and ROR- $\gamma$ t and enhanced the expression of TGF- $\beta$ and Foxp3 in mice with immune liver injury. Together, these findings suggested that HBG reduced immune liver injury by controlling the balance of Th1/Th2 and Th17/Tregs.

Previous studies have shown that IL-6 is an important regulatory factor in the development of autoimmune diseases [33]. IL-6 plays an important role in the differentiation of Th17. The IL- 6 content in HBG decreased significantly, which may be the specific initial mechanism of the protective effect of HBG on liver injury. When IL-6 binds to its receptor, JAK kinase, especially, JAK1 and JAK2, promotes phosphorylation of the IL-6 receptor complex, while STAT3 binds to the latter for a short amount of time. Subsequently, STAT3 is phosphorylated by JAK, dissociates into a dimer, and is translated into nucleus. STAT3 plays an important role in cell growth, survival, proliferation, differentiation, and apoptosis [34]. In our study, HBG treatment abolished the increase in p-JAK1 and p-STAT3 in mice with liver injury. Previous studies have shown that the regulation of STAT3 and MAPKs was relative to the modulation of apoptosis [35]. In the development of ConA-induced immune liver injury, the STAT1 pathway in mouse hepatic stellate cells was activated, resulting in the release of IFN- $\beta$, and the released IFN- $\beta$ activates the STAT1 pathway in hepatocytes, leading to oxidative stress and subsequent apoptosis of hepatocytes [36, 37]. IRF1 is a transcription factor that controls transcription of many antiviral and apoptosis- 
related genes and is related to the level of oxidation in hepatocytes [36]. It is reported IRF1 can be specifically activated by STAT1 and STAT3 [38]. In our study, treatment with HBG effectively reduced the expression of IFN- $\beta$, STAT1, and IRF1. Thus, these findings suggested that HBG reduced apoptosis could be related to the inhibition of JAK1/ STATs/IRF1 signaling pathway.

Previous studies have shown that JNK was involved in the activation of mitochondria [39, 40]. It has previously been reported that blocking the generation of ROS in the liver almost completely blocked the activation of JNK and decreased the liver damage, suggesting that ROS were the main contributor of JNK activation [41]. Moreover, studies have shown that ConA-induced immunological liver injury decreased significantly with the inhibition of JNK phosphorylation [42-44]. JNK may promote cell death through different mechanisms in different cells. SOD is an important mediator of the primary line of defense against the harmful effects of ROS [45]. In addition, oxidative stress has been considered the main factor of ConA-induced liver injury, which can damage DNA, induce apoptosis, and promote the production of inflammatory cytokines. MDA, a residual product of lipid peroxidation, is often used to indicate the oxidative status of a cell [46]. In this study, we observed that treatment with HBG significantly inhibited the production of ROS and MDA and increased the activity of SOD in mice with liver injury. Furthermore, the protein expression of p-JNK, p-ERK, p-p38, and cleaved caspase- 3 was reduced by HBG treatment. Taken together, our findings indicated that the protective effect of HBG on ConA-induced immune liver injury was related to the MAPK family, and that HBG reduced active oxygen and restored antioxidant enzymes of the body to decrease the activation of JNK, thereby inhibiting apoptosis.

\section{Conclusions}

The protective effect of HBG involved regulating the immune balance and inhibiting JAK1/STATs/IRF1 signaling, thereby reducing apoptosis induced by JNK activation (Figure 5). These findings suggest that HBG may be a promising potential therapeutic agent for immune liver injury. Considering that the chemical substances of HBG are complex, additional studies are essential to elucidate the specific chemical components of HBG that play a therapeutic role in immune liver injury.

\section{Data Availability}

The datasets used and/or analyzed during the current study are available from the corresponding author upon reasonable request.

\section{Disclosure}

The funder participated in data collection and analysis of the manuscript.

\section{Conflicts of Interest}

The authors declare that they have no conflicts of interest.

\section{Acknowledgments}

The authors would like to thank all the colleagues and students who contributed to this study. This work was supported by the Scientific Research Project of Education Department of Hubei Province (D20192003).

\section{References}

[1] M. P. Manns, A. W. Lohse, and D. Vergani, "Autoimmune hepatitis--Update 2015," Journal of Hepatology, vol. 62, no. 1 Suppl, pp. S100-S111, 2015.

[2] E. L. Krawitt, "Autoimmune hepatitis," New England Journal of Medicine, vol. 354, no. 1, pp. 54-66, 2006.

[3] B. Gao, W. I. Jeong, and Z. Tian, "Liver: an organ with predominant innate immunity," Hepatology, vol. 47, no. 2, pp. 729-736, 2008.

[4] Q. Wang, F. Yang, Q. Miao, E. L. Krawitt, M. E. Gershwin, and $\mathrm{X}$. Ma, "The clinical phenotypes of autoimmune hepatitis: a comprehensive review," Journal of Autoimmunity, vol. 66, pp. 98-107, 2016.

[5] N. Nakamoto, T. Amiya, R. Aoki et al., "Commensal Lactobacillus controls immune tolerance during acute liver injury in mice," Cell Reports, vol. 21, no. 5, pp. 1215-1226, 2017.

[6] E. I. Zuniga, M. Macal, G. M. Lewis, and J. A. Harker, "Innate and adaptive immune regulation during chronic viral infections," Annual Review of Virology, vol. 2, no. 1, pp. 573-597, 2015.

[7] J. Schümann, J. Prockl, A. K. Kiemer, A. M. Vollmar, R. Bang, and G. Tiegs, "Silibinin protects mice from T cell-dependent liver injury," Journal of Hepatology, vol. 39, no. 3, pp. 333-340, 2003.

[8] G. H. Stummvoll, R. J. DiPaolo, E. N. Huter et al., "Th1, Th2, and Th17 effector T cell-induced autoimmune gastritis differs in pathological pattern and in susceptibility to suppression by regulatory T cells," The Journal of Immunology, vol. 181, no. 3, pp. 1908-1916, 2008.

[9] C.-F. Le, T. H. Kailaivasan, S.-C. Chow, Z. Abdullah, S.-K. Ling, and C.-M. Fang, "Phytosterols isolated from Clinacanthus nutans induce immunosuppressive activity in murine cells," International Immunopharmacology, vol. 44, pp. 203-210, 2017.

[10] R. Liberal, C. R. Grant, M. S. Longhi, G. Mieli-Vergani, and D. Vergani, "Regulatory T cells: mechanisms of suppression and impairment in autoimmune liver disease," IUBMB Life, vol. 67 , no. 2 , pp. 88-97, 2015.

[11] H. Huang and Z. Deng, "Adoptive transfer of regulatory T cells stimulated by allogeneic hepatic stellate cells mitigates liver injury in mice with concanavalin A-induced autoimmune hepatitis," Biochemical and Biophysical Research Communications, vol. 512, no. 1, pp. 14-21, 2019.

[12] X. Zhao, S. Ding, C. Geng et al., "Anti-CD200 attenuates concanavalin A induced hepatitis via modulating the imbalance of CD4(+) T lymphocyte differentiation in mice," American Journal of Translational Research, vol. 10, no. 12, pp. 4202-4209, 2018.

[13] P. Cheng, K. Chen, Y. Xia et al., "Hydrogen sulfide, a potential novel drug, attenuates concanavalin A-induced hepatitis," Drug Design, Development and Therapy, vol. 8, pp. 1277-1286, 2014.

[14] T. A. Fleisher, "Apoptosis," Annals of Allergy, Asthma, and Immunology, vol. 78, no. 3, pp. 245-250, 1997.

[15] T. Torisu, M. Nakaya, S. Watanabe et al., "Suppressor of cytokine signaling 1 protects mice against concanavalin A-induced hepatitis by inhibiting apoptosis," Hepatology, vol. 47, no. 5, pp. 1644-1654, 2008. 
[16] C. A. Bradham, J. Plümpe, M. P. Manns, D. A. Brenner, and C. Trautwein, "Mechanisms of hepatic toxicity. I. TNF-induced liver injury," American Journal of Physiology-Gastrointestinal and Liver Physiology, vol. 275, no. 3, pp. G387-G392, 1998.

[17] H. Kawamura, S. Govindarajan, F. Aswad et al., "HCV core expression in hepatocytes protects against autoimmune liver injury and promotes liver regeneration in mice," Hepatology, vol. 44, no. 4, pp. 936-944, 2006.

[18] T. Wu, L. Jiang, A. Hajiakber, and Y Sun, "Study on new extraction technology and protective effect of hugan buzure granule on liver injury in mice," China journal of Chinese Materia Medica, vol. 36, no. 4, pp. 429-433, 2011.

[19] Q. Luo, J. Ding, L. Zhu, F. Chen, and L. Xu, "Hepatoprotective effect of wedelolactone against concanavalin A-induced liver injury in mice," American Journal of Chinese Medicine, vol. 46, no. 4, pp. 819-833, 2018.

[20] J. Luan, X. Zhang, S. Wang et al., "NOD-like receptor protein 3 inflammasome-dependent IL- $1 \beta$ accelerated ConA-induced hepatitis," Frontiers in Immunology, vol. 9, p. 758, 2018.

[21] M. Sternak, A. Jakubowski, E. Czarnowska et al., "Differential involvement of IL-6 in the early and late phase of 1-methylnicotinamide (MNA) release in Concanavalin A-induced hepatitis," International Immunopharmacology, vol. 28, no. 1, pp. 105-114, 2015.

[22] K. Wang, "Autophagy and apoptosis in liver injury," Cell Cycle, vol. 14, no. 11, pp. 1631-1642, 2015.

[23] R. Ksontini, D. B. Colagiovanni, M. D. Josephs et al., "Disparate roles for TNF-alpha and Fas ligand in concanavalin A-induced hepatitis," The Journal of Immunology, vol. 160, no. 8, pp. 4082-4089, 1998.

[24] I. G. McFarlane, "Pathogenesis of autoimmune hepatitis," Biomedicine and pharmacotherapy = Biomedecine and pharmacotherapie, vol. 53, no. 5-6, pp. 255-263, 1999.

[25] G. Tiegs, "Cellular and cytokine-mediated mechanisms of inflammation and its modulation in immune-mediated liver injury," Zeitschrift für Gastroenterologie, vol. 45, no. 1, pp. 63-70, 2007.

[26] D. Vergani and G. Mieli-Vergani, "Aetiopathogenesis of autoimmune hepatitis," World Journal of Gastroenterology, vol. 14, no. 21, pp. 3306-3312, 2008.

[27] D. Tedesco and A. Grakoui, "Environmental peer pressure: CD4+T cell help in tolerance and transplantation," Liver Transplantation, vol. 24, no. 1, pp. 89-97, 2018.

[28] S. Kusters, F. Gantner, G. Kunstle, and G. Tiegs, "Interferon gamma plays a critical role in T cell-dependent liver injury in mice initiated by concanavalin A," Gastroenterology, vol. 111, no. 2, pp. 462-471, 1996.

[29] C. Günther, G.-W. He, A. E. Kremer et al., "The pseudokinase MLKL mediates programmed hepatocellular necrosis independently of RIPK3 during hepatitis," Journal of Clinical Investigation, vol. 126, no. 11, pp. 4346-4360, 2016.

[30] X. Tian, Y. Liu, X. Liu, S. Gao, and X. Sun, "Glycyrrhizic acid ammonium salt alleviates Concanavalin A-induced immunological liver injury in mice through the regulation of the balance of immune cells and the inhibition of hepatocyte apoptosis," Biomedicine \& Pharmacotherapy, vol. 120, Article ID 109481, 2019.

[31] M. S. Longhi, Y. Ma, D. P. Bogdanos, P. Cheeseman, G. MieliVergani, and D. Vergani, "Impairment of CD4+CD25+ regulatory T-cells in autoimmune liver disease," Journal of Hepatology, vol. 41, no. 1, pp. 31-37, 2004.

[32] M. S. Longhi, Y. Ma, R. R. Mitry et al., "Effect of CD4+CD25+ regulatory $\mathrm{T}$-cells on $\mathrm{CD} 8 \mathrm{~T}$-cell function in patients with autoimmune hepatitis," Journal of Autoimmunity, vol. 25, no. 1, pp. 63-71, 2005.

[33] F. Horn, C. Henze, and K. Heidrich, "Interleukin-6 signal transduction and lymphocyte function," Immunobiology, vol. 202, no. 2, pp. 151-167, 2000.

[34] M. A. Bill, J. R. Fuchs, C. Li et al., "The small molecule curcumin analog FLLL32 induces apoptosis in melanoma cells via STAT3 inhibition and retains the cellular response to cytokines with anti-tumor activity," Molecular Cancer, vol. 9, no. 1 , p. $165,2010$.

[35] Q. Chen, D.-Y. Ouyang, M. Geng et al., "Valproic acid exhibits biphasic effects on apoptotic cell death of activated lymphocytes through differential modulation of multiple signaling pathways," Journal of Immunotoxicology, vol. 8, no. 3, pp. 210-218, 2011.

[36] R. Rani, S. Kumar, A. Sharma et al., "Mechanisms of concanavalin A-induced cytokine synthesis by hepatic stellate cells: distinct roles of interferon regulatory factor-1 in liver injury," Journal of Biological Chemistry, vol. 293, no. 48, pp. 18466-18476, 2018.

[37] R. Rani, A. Tandon, J. Wang, S. Kumar, and C. R. Gandhi, "Stellate cells orchestrate concanavalin A-induced acute liver damage," American Journal Of Pathology, vol. 187, no. 9, pp. 2008-2019, 2017.

[38] T. Sato, C. Selleri, N. S. Young, and J. P. Maciejewski, "Inhibition of interferon regulatory factor-1 expression results in predominance of cell growth stimulatory effects of interferon$\gamma$ due to phosphorylation of Stat1 and Stat3," Blood, vol. 90, no. 12 , pp. 4749-4758, 1997.

[39] H. Liu, C. R. Lo, and M. J. Czaja, "NF- $\kappa$ B inhibition sensitizes hepatocytes to TNF-induced apoptosis through a sustained activation of JNK and c-Jun," Hepatology, vol. 35, no. 4, pp. 772-778, 2002.

[40] Y. Wang, R. Singh, J. H. Lefkowitch, R. M. Rigoli, and M. J. Czaja, "Tumor necrosis factor-induced toxic liver injury results from JNK2-dependent activation of caspase- 8 and the mitochondrial death pathway," Journal of Biological Chemistry, vol. 281, no. 22, pp. 15258-15267, 2006.

[41] T. G. Lehmann, M. D. Wheeler, R. F. Schwabe et al., "Gene delivery of $\mathrm{Cu} / \mathrm{Zn}$-superoxide dismutase improves graft function after transplantation of fatty livers in the rat," Hepatology, vol. 32, no. 6, pp. 1255-1264, 2000.

[42] H.-M. Ni, X. Chen, W.-X. Ding, M. Schuchmann, and X.-M. Yin, "Differential roles of JNK in ConA/GalN and ConA-induced liver injury in mice," American Journal Of Pathology, vol. 173, no. 4, pp. 962-972, 2008.

[43] J. Li, Y. Xia, T. Liu et al., "Protective effects of astaxanthin on ConA-induced autoimmune hepatitis by the JNK/p-JNK pathway-mediated inhibition of autophagy and apoptosis," PLoS One, vol. 10, no. 3, Article ID e0120440, 2015.

[44] A. Gonzalez-Rodriguez, B. Reibert, T. Amann, R. Constien, C. M. Rondinone, and Á. M. Valverde, "In vivo siRNA delivery of Keap1 modulates death and survival signaling pathways and attenuates concanavalin-A-induced acute liver injury in mice," Dis Model Mech, vol. 7, no. 9, pp. 1093-1100, 2014.

[45] M. H. Sharawy, D. S. El-Agamy, A. A. Shalaby, and E.-S. M. Ammar, "Protective effects of methyl palmitate against silica-induced pulmonary fibrosis in rats," International Immunopharmacology, vol. 16, no. 2, pp. 191-198, 2013.

[46] R. Pacifici, A. I. Fiaschi, L. Micheli et al., "Immunosuppression and oxidative stress induced by acute and chronic exposure to cocaine in rat," International Immunopharmacology, vol. 3, no. 4, pp. 581-592, 2003. 